\title{
Technical note: Time lag correction of aquatic eddy covariance data measured in the presence of waves
}

\author{
P. Berg ${ }^{1}$, C. E. Reimers ${ }^{2}$, J. H. Rosman ${ }^{3}$, M. Huettel ${ }^{4}$, M. L. Delgard ${ }^{1}$, M. A. Reidenbach ${ }^{1}$, and H. T. Özkan-Haller ${ }^{2}$ \\ ${ }^{1}$ Department of Environmental Sciences, University of Virginia, Charlottesville, Virginia, USA \\ ${ }^{2}$ College of Earth, Ocean and Atmospheric Sciences, Oregon State University, Corvallis, Oregon, USA \\ ${ }^{3}$ Institute of Marine Sciences, University of North Carolina at Chapel Hill, Morehead City, North Carolina, USA \\ ${ }^{4}$ Department of Earth, Ocean and Atmospheric Science, Florida State University, Tallahassee, Florida, USA
}

Correspondence to: P. Berg (pb8n@virginia.edu)

Received: 28 April 2015 - Published in Biogeosciences Discuss.: 8 June 2015

Revised: 28 October 2015 - Accepted: 1 November 2015 - Published: 26 November 2015

\begin{abstract}
Extracting benthic oxygen fluxes from eddy covariance time series measured in the presence of surface gravity waves requires careful consideration of the temporal alignment of the vertical velocity and the oxygen concentration. Using a model based on linear wave theory and measured eddy covariance data, we show that a substantial error in flux can arise if these two variables are not aligned correctly in time. We refer to this error in flux as the time lag bias. In one example, produced with the wave model, we found that an offset of $0.25 \mathrm{~s}$ between the oxygen and the velocity data produced a 2 -fold overestimation of the flux. In another example, relying on nighttime data measured over a seagrass meadow, a similar offset reversed the flux from an uptake of $-50 \mathrm{mmol} \mathrm{m}^{-2} \mathrm{~d}^{-1}$ to a release of $40 \mathrm{mmol} \mathrm{m}^{-2} \mathrm{~d}^{-1}$. The bias is most acute for data measured at shallow-water sites with short-period waves and low current velocities. At moderate or higher current velocities ( $>5-10 \mathrm{~cm} \mathrm{~s}^{-1}$ ), the bias is usually insignificant. The widely used traditional time shift correction for data measured in unidirectional flows, where the maximum numerical flux is sought, should not be applied in the presence of waves because it tends to maximize the time lag bias or give unrealistic flux estimates. Based on wave model predictions and measured data, we propose a new time lag correction that minimizes the time lag bias. The correction requires that the time series of both vertical velocity and oxygen concentration contain a clear periodic wave signal. Because wave motions are often evident in eddy covariance data measured at shallow-water sites, we encourage more work on identifying new time lag corrections.
\end{abstract}

\section{Introduction}

\subsection{Background}

Eddy covariance (or eddy correlation) measurements of scalar fluxes under water have been performed for many years. The earliest studies focused on measurements of heat fluxes under sea ice (McPhee, 1992; Fukuchi et al., 1997; Shirasawa et al., 1997) and salt fluxes in a salt wedge estuary (Partch and Smith, 1978). More recently, concurrent heat and salt fluxes have also been measured over marine permeable sandy sediments as tracers for groundwater seepage (Crusius et al., 2008). Over the last 10 years, the aquatic eddy covariance technique has become a widely accepted approach for measuring oxygen fluxes between benthic ecosystems and the overlying water (Berg et al., 2003). In that time, the number of users has grown rapidly, and the technique has been applied under very different field settings such as muddy and sandy sediments (Berg et al., 2003; Kuwae et al., 2006; Glud et al., 2010), deep ocean sediments (Berg et al., 2009), coral reefs (Long et al., 2013; Cathalot et al., 2015; Rovelli et al., 2015), and seagrass meadows (Hume et al., 2011; Rheuban et al., 2014; Long et al., 2015). With a few exceptions, all of the recently published aquatic eddy covariance studies have focused on oxygen fluxes. Oxygen fluxes are also the focus of this study, but its findings apply to all scalar fluxes.

The aquatic eddy covariance technique has advantages over other methods for measuring fluxes between the benthic environment and the overlying water, including its noninvasive nature (Lorrai et al., 2010), high temporal resolution (Rheuban and Berg, 2013), and ability to integrate over 
a large benthic surface (Berg et al., 2007). As a result, the technique is poised for widespread use in aquatic science, analogous to the development in atmospheric boundary layer research where the equivalent approach is now the preferred standard method for measuring land-air fluxes (Baldocchi, 2003). As part of the further development of the technique in aquatic environments, a few challenges must be addressed. One of them is that procedures for calculating fluxes from raw data must be refined to minimize errors and uncertainties that may be unique to aquatic applications. The procedures used today are largely adapted directly from atmospheric boundary layer research, where the eddy covariance technique has been used for more than 6 decades (Priestley and Swinbank, 1947; Swinbank, 1951).

\subsection{Formulation of problem}

This study focuses on estimating oxygen fluxes under a set of field conditions that do not occur in the atmosphere but are very common under water at shallow-water sites. Here, surface gravity waves can cause oscillatory motion throughout the water column to the benthic surface and give rise to a unique set of challenges when eddy fluxes are extracted. Some of these challenges are directly linked to limitations of the eddy covariance instrumentation available today.

Although fast-responding oxygen sensors are used in eddy covariance measurements, their speed is still limited relative to the velocity sensor (e.g., a Vector acoustic Doppler velocimeter (ADV) from Nortek AS). Clark-type oxygen microelectrodes used for eddy covariance typically have response times $\left(t_{90 \%}\right)$ of 0.2 to $0.5 \mathrm{~s}$ (Berg et al., 2003; Attard et al., 2015; Donis et al., 2015). Newer optical sensors that have been developed in recent years have comparable or somewhat longer response times of 0.2 to $0.8 \mathrm{~s}$ (Chipman et al., 2012; Murniati et al., 2015; Berg et al., 2015). This means that the time series of the two key variables from which eddy fluxes are derived, the vertical velocity and oxygen concentration, are never perfectly aligned in time. Also, because the ADV derives its data from acoustic backscatter of suspended particles moving through its $\sim 2 \mathrm{~cm}^{3}$ measuring volume, the oxygen sensor must be positioned outside of this volume to avoid disturbing the velocity measurements. Depending on the instantaneous flow direction and magnitude, this physical separation can increase or decrease the time lag between the two time series.

\subsection{Traditional time lag correction}

For measurements in unidirectional flows with thin fastresponding Clark-type microelectrodes $\left(t_{90 \%}<0.3 \mathrm{~s}\right)$ that can be positioned at the edge of the ADV's measuring volume, the temporal misalignment usually has insignificant effects on the flux estimate (Berg et al., 2013). Inspection of the cumulative co-spectrum between the vertical velocity and the oxygen concentration can confirm or reject this on a case-

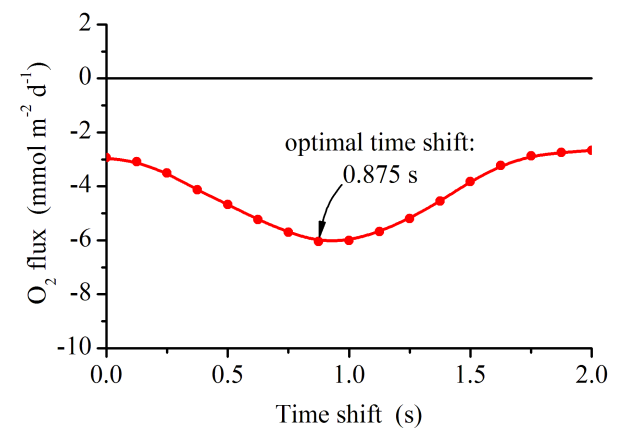

Figure 1. Example of traditional time lag correction of $8 \mathrm{~Hz}$ eddy covariance data measured with a dual oxygen-temperature sensor in unidirectional river flow. The oxygen data are moved back in time relative to the velocity data. The "best" flux estimate is defined as the maximum numeric flux value and corresponds to an optimal time shift of $0.875 \mathrm{~s}$.

by-case basis. Specifically, a correction is unnecessary in the absence of a local extremum in the co-spectrum near $1 \mathrm{~Hz}$ (Berg et al., 2013). In situations when the misalignment does affect the calculated eddy flux, a straightforward correction has been adapted from atmospheric boundary layer research, in which the oxygen data are successively shifted in time relative to the velocity data in order to find the maximum numeric flux, or cross-correlation (Fan et al., 1990; McGinnis et al., 2008; Lorrai et al., 2010). Figure 1 shows an example of this correction applied to data measured in a river with a unidirectional flow of $\sim 16 \mathrm{~cm} \mathrm{~s}^{-1}$ and using a new dual oxygen-temperature sensor. This sensor has a $1 \mathrm{~cm}$ tip diameter and a response time $\left(t_{90 \%}\right)$ for oxygen of $0.51 \mathrm{~s}$, which was measured by inserting it from air into a water bath (Berg et al., 2015). The center of the sensor was positioned $\sim 2.5 \mathrm{~cm}$ downstream from the center of the ADV's measuring volume.

\subsection{Scope of work}

We will show that even small temporal misalignment between the vertical velocity and the oxygen concentration, inherently imbedded in all present eddy covariance data, can lead to significant errors in fluxes extracted from data measured in the presence of waves. We refer to this error as the time lag bias and show that the traditional time lag correction illustrated in Fig. 1 will fail. Using a model based on linear wave theory and measured data, we explain the cause of the bias and examine its potential magnitude. We then propose a new correction for this time lag, which minimizes the time lag bias, and test it on two sets of measured data. We encourage more work on identifying new time lag corrections and provide a link from where all of the raw data used in this study can be downloaded. 

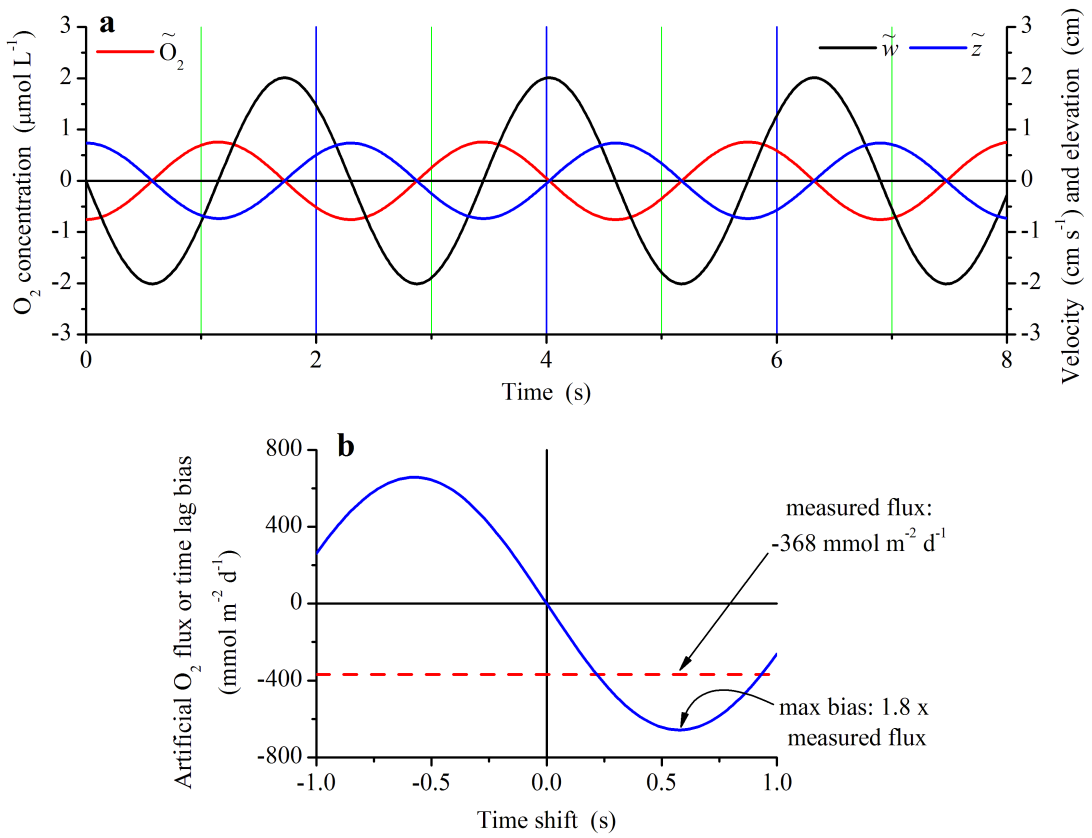

Figure 2. Illustration, using modeled data, of the substantial error, or time lag bias, that can arise in eddy flux estimates from data measured in the presence of waves. Parameters for the model were taken from Berg and Huettel (2008). Panel (a): fluctuations due to wave motion only in vertical velocity $(\widetilde{w})$, oxygen concentration $\left(\widetilde{\mathrm{O}}_{2}\right)$, and vertical displacement $(\widetilde{z}$, see its definition and use in the text). Panel $(\mathbf{b})$ : time lag bias (blue line) at different imposed time shifts, relative to the assumed real flux (red line), which was used to parameterize the model. Positive time shifts move the oxygen data back in time relative to the velocity data.

\section{Methods}

\subsection{Illustration of the problem using a wave model}

The two-dimensional model for progressive waves and their effect on the oxygen concentration at a fixed height above the sediment surface is presented in Appendix A. In short, the model, which is based on linear wave theory, describes the horizontal and vertical wave orbital velocities and the variation in oxygen concentration generated by the up and down movement of the natural oxygen gradient as a function of time as they would be recorded under ideal conditions, without any time lag and at exactly the same location. It is assumed that any local horizontal variations in oxygen uptake or release at the sediment surface have been smeared out by turbulent mixing at this location. Model parameter values (Table A1, Appendix A), including a sediment uptake of $-368 \mathrm{mmol} \mathrm{m}^{-2} \mathrm{~d}^{-1}$, were adapted or estimated from the eddy covariance data reported by Berg and Huettel (2008) from a shallow-water site exposed to surface waves. The values are well within the range for which linear wave theory applies. Specifically, ratios of wave amplitude to wavelength and wave amplitude to water depth should both be $\ll 1$ (Kundu, 1990). Using the equations listed in Appendix A gives a wavelength of $7 \mathrm{~m}$, and, therefore, ratios of 0.008 and 0.04 , respectively. The model was used to generate theoretical time series of the wave velocity and wave-generated vari- ation in oxygen concentration that were then shifted in time relative to one another to illustrate how a time lag can affect the flux calculation.

The modeled data were found to mimic the averaged nighttime conditions reported by Berg and Huettel (2008) well. As illustrated in Fig. 2a, the simulated vertical wave velocity $(\widetilde{w})$ varied between $\sim \pm 2 \mathrm{cms}^{-1}$, while the associated up and down movement of the natural oxygen gradient established by the sediment's uptake produced $\mathrm{O}_{2}$ concentration oscillations $\left(\widetilde{\mathrm{O}}_{2}\right)$ of $\sim \pm 1 \mu \mathrm{mol} \mathrm{L}-1$. These data are for the case where the velocity and oxygen concentration are "recorded" without any time lag and at exactly the same location. Furthermore, the simulated data exclude any current-driven turbulence so that variations in velocity and concentration are due to wave orbital motion only. The potential for a significant time lag bias (either positive or negative), which can arise from the wave signal alone in eddy covariance data, becomes apparent when shifting the oxygen data stepwise in time relative to the velocity data and recalculating the eddy flux for each shift (Fig. 2b).

The model and its results in Fig. 2 reveal the following key characteristics of the time lag bias due to waves:

- As soon as there is a time lag between the velocity and the oxygen measurements (time shift $\neq 0$, Fig. $2 b$ ), a bias in the flux estimate will arise. 
- Because oxygen sensors do not have an instant response and because velocity and oxygen data are not measured at exactly the same location, fluxes may be biased if wave-driven fluctuations in velocity and oxygen concentration can be identified.

- The size of the time lag bias scales with the mean oxygen concentration gradient in the water column, and, therefore, it scales with the real flux.

- The time lag bias can have the opposite sign of the real flux.

- The maximum time lag bias can exceed the real flux.

- For short-period waves, here $2.3 \mathrm{~s}$, a time lag of only $0.20 \mathrm{~s}$ can give a bias equal to the real flux.

- The traditional time shift correction, which works well in unidirectional flow (Fig. 1), will tend to identify the time shift associated with the maximum time lag bias.

- The time lag bias can be minimized if the appropriate time shift is applied (Fig. 2b).

The vertical gradient in oxygen concentration is less pronounced for field situations with substantial vertical turbulent mixing. As a result, eddy fluxes calculated from data measured at sites with significant unidirectional currents and rough sediment surfaces, which both stimulate vertical mixing (Rattray and Mitsuda, 1974; Boudreau and Jorgensen, 2001), will be less sensitive to time lag bias, even if orbital wave motions are present. The example in Fig. 2, where the maximum bias was found to be $180 \%$ of the real flux, was based on a mean current velocity of $1.0 \mathrm{~cm} \mathrm{~s}^{-1}$ and a sediment surface roughness parameter of $2 \mathrm{~mm}$ (Table A1). For rougher surfaces, for example with a roughness of $10 \mathrm{~mm}$, additional simulations showed that the maximum bias decreased from 180 to $110 \%$ of the real flux. A much larger decrease in maximum bias was seen with increasing current velocity as illustrated in Fig. 3. For example, an increase in velocity from 1 to $5 \mathrm{~cm} \mathrm{~s}^{-1}$ or from 1 to $10 \mathrm{~cm} \mathrm{~s}^{-1}$ reduced the time lag bias by a factor of 5 and 10 , respectively, as the vertical gradient was reduced.

When using the eddy covariance instrumentation available today, there will always be a time lag between the velocity and the oxygen data, and, therefore, the sensitivity of the flux calculation to even small time lags, as illustrated in Fig. 2b, can compromise the eddy flux estimated from data measured in the presence of waves.

\subsection{Illustration of new time lag correction using wave model data}

In addition to illustrating the time lag bias, the modeled data in Fig. 2a also point to a new approach for a time lag correction. From $\widetilde{w}$, the vertical displacement due to wave orbital

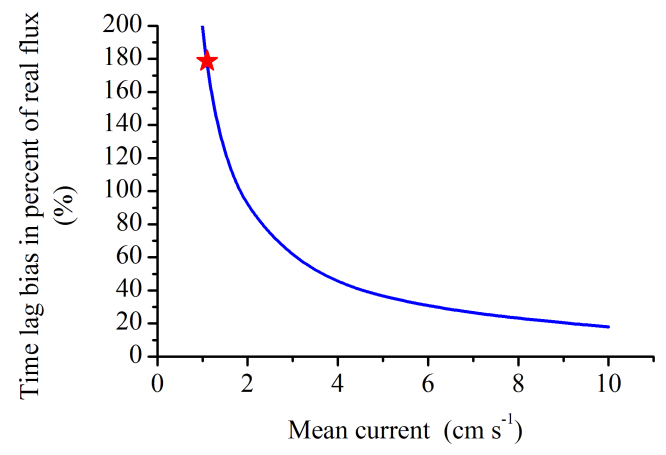

Figure 3. Decrease in maximum bias with increasing current velocity. The star represents the modeled data shown in Fig. $2 b$ where the maximum bias is $180 \%$ of the assumed real flux. Except for the current velocity, derived friction velocity, and derived turbulent eddy diffusivity (see Appendix A), all other model parameters were kept constant.

motion, $\widetilde{z}$, can be estimated as

$\widetilde{z}=\int \widetilde{w} \mathrm{~d} t$.

This variable, also shown in Fig. 2a, expresses the instantaneous relative elevation of a water parcel that is moved up and down at the vertical wave orbital velocity $\widetilde{w}$. Defining the positive $z$ direction upward, $\widetilde{z}$ increases when $\widetilde{w}$ is positive, and vice versa (Fig. 2a). Due to the positive gradient in mean oxygen concentration created by the sediment's consumption of oxygen, a minimum in $\widetilde{\mathrm{O}}_{2}$ will coincide exactly with a maximum in $\widetilde{z}$ in the absence of a time lag, and vice versa (Fig. 2a). Because this combination corresponds to a minimum in cross-correlation (most negative cross-correlation) of $\widetilde{z}$ and $\widetilde{\mathrm{O}}_{2}$, a new correction for the time lag in measured data can be defined by shifting the $\widetilde{\mathrm{O}}_{2}$ data relative to the $\widetilde{z}$ data until this minimum is located. If instead, the sediment releases oxygen due to benthic photosynthetic production, the mean oxygen concentration gradient is negative and a minimum in $\widetilde{\mathrm{O}}_{2}$ will be matched by a minimum in $\widetilde{z}$, and vice versa. In this case, the time lag correction can be defined as giving a maximum in cross-correlation of $\widetilde{z}$ and $\widetilde{\mathrm{O}}_{2}$. As a result of these two different situations, in which the sediment consumes or releases oxygen, a general correction can be defined by locating maxima or minima in the cross-correlation of $\widetilde{z}$ and $\widetilde{\mathrm{O}}_{2}$. Complications in this correction arise if there is no clear vertical gradient in mean oxygen concentration, for example at dawn and dusk, when oxygen production may match respiration, or in situations where vertical mixing due to substantial current is so vigorous that the vertical oxygen gradient diminishes. These cases are discussed in detail below. 

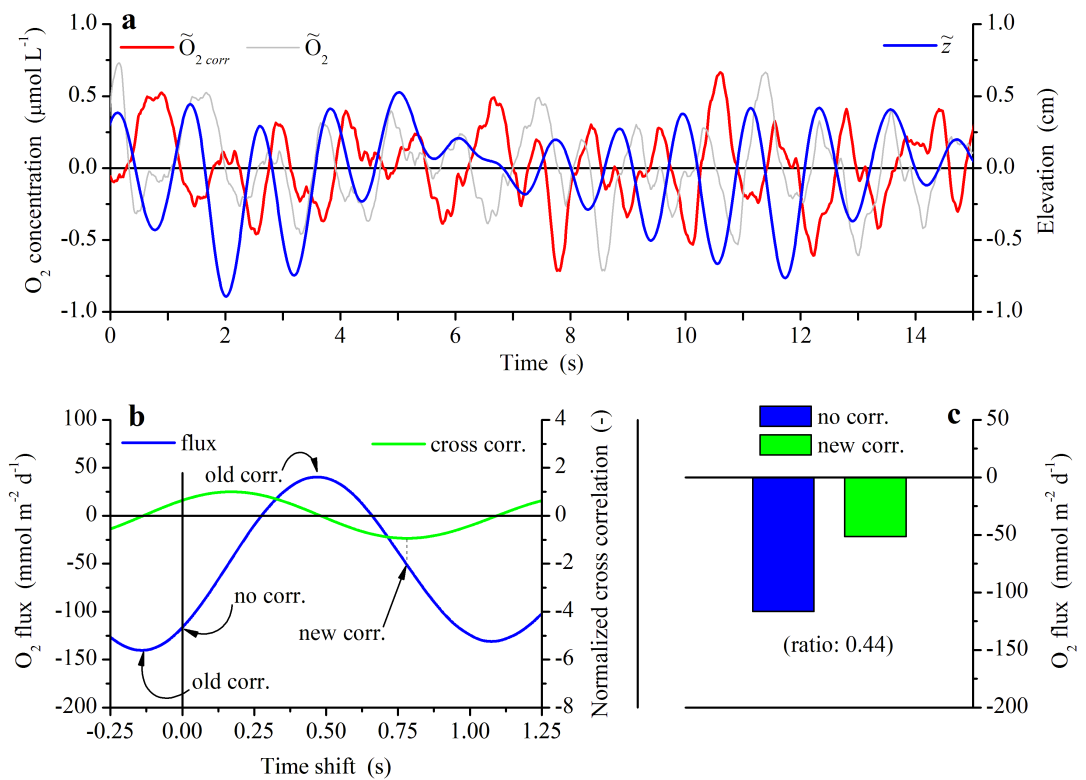

Figure 4. Illustration of the new time lag correction for a $15 \mathrm{~min}$ long data segment measured during nighttime over a dense seagrass meadow. Panel (a): $15 \mathrm{~s}$ data segment of the larger $15 \mathrm{~min}$ segment showing oxygen concentration fluctuations due to wave motions before $\left(\widetilde{\mathrm{O}}_{2}\right)$ and after the time lag correction $\left(\widetilde{\mathrm{O}}_{2 \text { corr }}\right)$ and vertical displacement $\widetilde{z}$ ) calculated from Eq. (1). The $64 \mathrm{~Hz}$ data were smoothed by a 17 -point $(0.27 \mathrm{~s})$ running average to better illustrate the wave signal. Panel (b): eddy flux calculated for the 15 min period for different time shifts and the associated cross-correlation of $\widetilde{z}$ and $\widetilde{\mathrm{O}}_{2}$. Positive time shifts move the oxygen data back in time relative to the velocity data. Panel (c): oxygen flux calculated without time shift correction and with the new time lag correction. The latter was defined as the shift that gave a minimum in cross-correlation of $\widetilde{z}$ and $\widetilde{\mathrm{O}}_{2}$ as illustrated in (b).

\subsection{Illustration of new time lag correction using measured data}

Figure 4 shows an example of the new correction applied to a 15 min measured eddy covariance data segment, which is the typical time interval used to calculate one eddy flux value (Berg et al., 2003). The data were measured during nighttime over a dense seagrass meadow using a new robust oxygen optode with no stirring sensitivity and a response time $\left(t_{90 \%}\right)$ of $0.51 \mathrm{~s}$ when inserted from air into a water bath (Berg et al., 2015). The measuring height was $30 \mathrm{~cm}$ above the sediment surface, water depth was $90 \mathrm{~cm}$, the significant wave height was $5 \mathrm{~cm}$, wave velocity was $2.6 \mathrm{~cm} \mathrm{~s}^{-1}$, and the mean current velocity was $0.8 \mathrm{~cm} \mathrm{~s}^{-1}$. To isolate the wave signal from other less dynamic variations in the velocity and oxygen concentration before calculating the cross-correlation of $\widetilde{z}$ and $\widetilde{\mathrm{O}}_{2}$, a 385 data point $(6.02 \mathrm{~s})$ running average was removed from the raw $64 \mathrm{~Hz}$ data. An example of the resulting data is shown in Fig. 4a. The eddy flux itself (Fig. 4b, c) was calculated following standard flux calculation procedures based on linear de-trending (Lee et al., 2004; Berg et al., 2009; Attard et al., 2014). Therefore, the estimated eddy flux represents the real flux plus any time lag bias. The $15 \mathrm{~s}$ data segment in Fig. 4a shows a distinct wave signal in $\widetilde{z}$ and $\widetilde{\mathrm{O}}_{2}$, which is a prerequisite for the time lag correction to work. Furthermore, these results, based on measured data, confirm the modeled results shown in Fig. 2 and reveal that the eddy flux (here the real flux plus the time lag bias) can vary substantially and attain both positive and negative values depending on the time shift applied (Fig. 4b). The results underline the notion that obtaining the best estimate of the real flux hinges on a properly determined time shift. In this case, the corrected flux was associated with a time shift of $0.78 \mathrm{~s}$, defined by a distinct minimum in cross-correlation of $\widetilde{z}$ and $\widetilde{\mathrm{O}}_{2}$ (Fig. $4 \mathrm{~b}$ ). This shift should be seen in relation to the sensor's own response time $\left(t_{90 \%}=0.51 \mathrm{~s}\right)$. These values and how they relate are discussed in detail below. The correction reduced the derived flux from -117 to $-51 \mathrm{mmol} \mathrm{m}^{-2} \mathrm{~d}^{-1}$, or to a value corresponding to $44 \%$ of the non-corrected flux (Fig. 4c).

Finally, the data revealed that the traditional time shift correction, where the maximum numerical flux is sought, will lead to substantial overestimation of the flux (Fig. 4b) if negative time shifts are allowed (moving the oxygen data forward in time relative to the velocity data). By contrast, if negative time shifts are excluded, a positive flux will be predicted (Fig. 4b), which does not make sense for nighttime measurements.

\section{Results}

The new time lag correction was tested on two eddy covariance data sets that were 4 and $16 \mathrm{~h}$ long. Both were measured at shallow-water sites and were characterized by relatively 

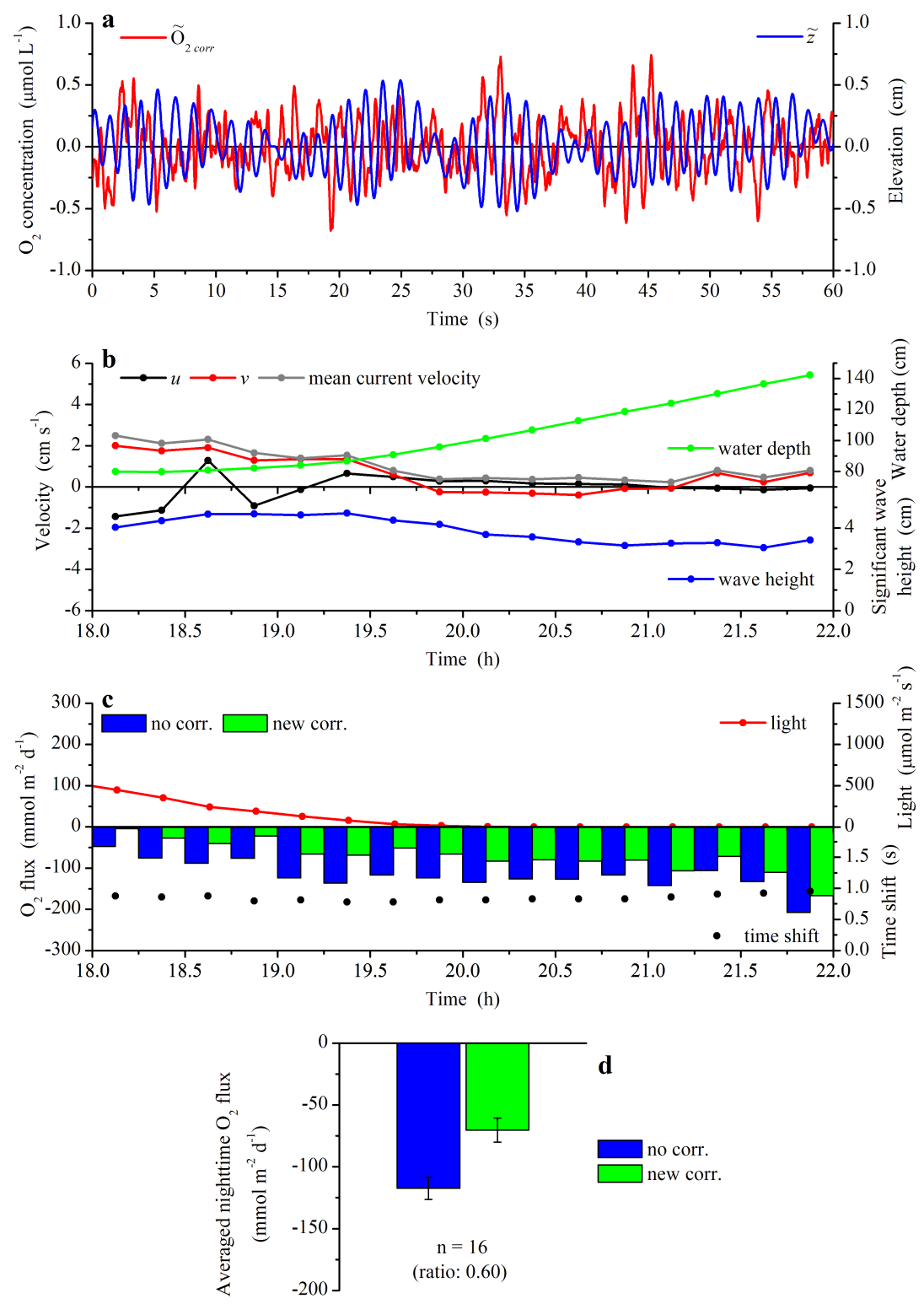

Figure 5. Application of the new time lag correction applied to a $4 \mathrm{~h}$ long data segment measured over a dense seagrass meadow. Panel (a): 60 s segment of wave-driven variation in oxygen concentration after correction $\left(\widetilde{\mathrm{O}}_{2 \text { corr }}\right)$ and vertical displacement $\left.\widetilde{z}\right)$ as calculated from Eq. (1). The $64 \mathrm{~Hz}$ data were smoothed by a 17-point $(0.27 \mathrm{~s})$ running average to better illustrate the wave signal. Panel (b): $15 \mathrm{~min}$ averages of the two horizontal velocity components $(u$ and $v$ ), mean current velocity, water depth, and significant wave height. Panel (c): oxygen flux, one per $15 \mathrm{~min}$, determined without and with the new correction, light (PAR) measured above the seagrass canopy, and the time shift. Panel (d): average flux for nighttime (time $>18.25 \mathrm{~h}$ ) before and after correction.

low current velocities and short-period waves, which caused clear wave-driven fluctuations in vertical velocity and oxygen concentration. Consequently, these two data examples had the characteristics expected to produce sizeable time lag biases. In both cases, the wave signal was separated from other less dynamic variations before calculating the crosscorrelation of $\widetilde{z}$ and $\widetilde{\mathrm{O}}_{2}$. The prior was done by subtracting a running average produced using a filter width of 4 times the wave period from the measured data.

\subsection{Application of new time lag correction: first example}

The first data set (Fig. 5) was measured at dusk over the same dense seagrass meadow and with the same fast-responding oxygen optode (Berg et al., 2015) as described in Sect. 2.3. Again, the measuring height was $30 \mathrm{~cm}$ above the sediment.

The $60 \mathrm{~s}$ data segment (Fig. 5a) shows, as the previous example (Fig. 4a), a distinct wave signal in $\widetilde{z}$ and $\widetilde{\mathrm{O}}_{2}$ with a 

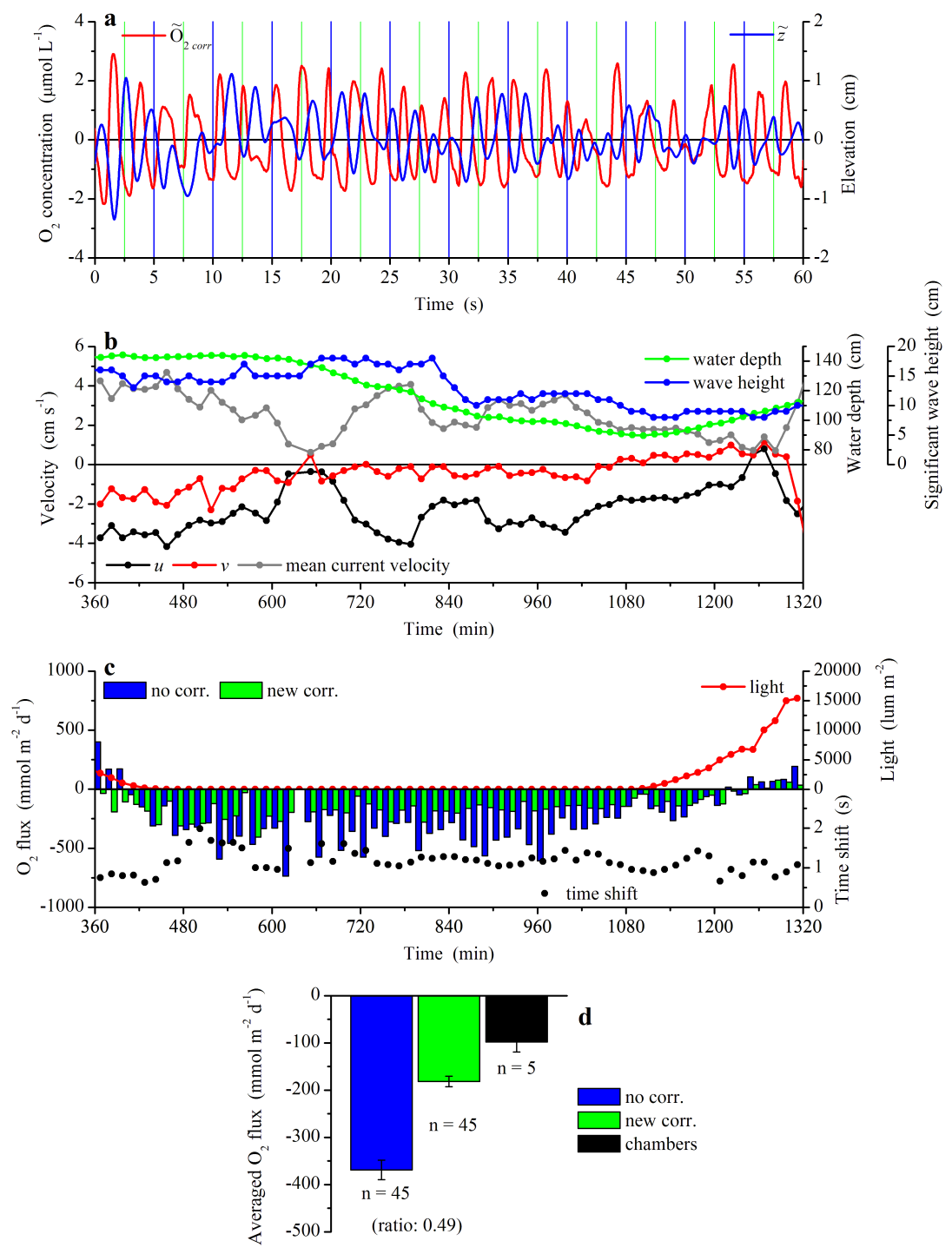

Figure 6. Application of the new time lag correction applied to a $16 \mathrm{~h}$ long data segment measured over a permeable sandy sediment and reported earlier by Berg and Huettel (2008). Panel (a): 60 s segment of wave-driven variation in oxygen concentration after correction $\left(\widetilde{\mathrm{O}}_{2 \text { corr }}\right)$ and vertical displacement $(\widetilde{z})$ as calculated from Eq. (1). The data are from when the wave action was at its maximum (time $\sim 620$ min). The $64 \mathrm{~Hz}$ data were smoothed by a 17 -point $(0.27 \mathrm{~s})$ running average to better illustrate the wave signal. Panel (b): 15 min averages of the two horizontal velocity components $(u$ and $v$ ), mean current velocity, water depth, and significant wave height. Panel (c): oxygen flux, one per 15 min, determined without and with the new correction, light measured above the sand, and the time shift. Panel (d): average flux for nighttime (450 $\mathrm{min}<$ time $<1095 \mathrm{~min}$ ) before and after correction and measured concurrently with in situ chambers.

$\sim 1.5 \mathrm{~s}$ period. Wave groups (i.e., sets of $1.5 \mathrm{~s}$ waves) with $\mathrm{a} \sim 11 \mathrm{~s}$ period are also visible. The significant wave height averaged $4 \mathrm{~cm}$ (Fig. 5b), wave velocity averaged $2.4 \mathrm{~cm} \mathrm{~s}^{-1}$, and the current changed in direction and also in strength between 0.2 and $2.5 \mathrm{~cm} \mathrm{~s}^{-1}$ with an average of $1.0 \mathrm{~cm} \mathrm{~s}^{-1}$, while the water depth varied between 80 and $140 \mathrm{~cm}$. Unambiguous variations in $\widetilde{z}$ and $\widetilde{\mathrm{O}}_{2}$, with amplitudes of $\sim 0.5 \mathrm{~cm}$ and $\sim 0.5 \mu \mathrm{mol} \mathrm{L}^{-1}$, respectively, allowed precise determination of minima in cross-correlation of $\widetilde{z}$ and $\widetilde{\mathrm{O}}_{2}$, which gave virtually the same time shift for every $15 \mathrm{~min}$ time interval used for individual flux estimates (Fig. 5c). The av- eraged time shift was $0.85 \pm 0.013 \mathrm{~s}$ (SE, $n=16$ ), and the correction reduced the averaged flux from $-117 \pm 8.9$ to $-70 \pm 9.7 \mathrm{mmol} \mathrm{m}^{-2} \mathrm{~d}^{-1}(\mathrm{SE}, n=16)$, or by a factor of 0.60 (Fig. 5d).

\subsection{Application of new time lag correction: second example}

The $16 \mathrm{~h}$ long data set, covering a period from late afternoon into the next day, was measured over a permeable sandy sediment, as previously reported by Berg and Huettel (2008). 
The measuring height was $12 \mathrm{~cm}$ above the sediment, and the oxygen concentration was measured with a Clark-type microelectrode. Parameters for the wave model (Figs. 2, 3) were determined from nighttime data from this deployment.

The $60 \mathrm{~s}$ data segment shown in Fig. 6a depicts the time when the wave action was at its maximum (time $\sim 620 \mathrm{~min}$ ). Currents were stronger and waves larger during this example, but the segment contains the same clear correlations between the wave-driven fluctuation in $\widetilde{z}$ and $\widetilde{\mathrm{O}}_{2}$ as found in the previous examples (Figs. 4a, 5a). The period of the waves was $\sim 2.3 \mathrm{~s}$, and $\widetilde{z}$ and $\widetilde{\mathrm{O}}_{2}$ had amplitudes of $\sim 1 \mathrm{~cm}$ and $\sim 2.5 \mu \mathrm{mol} \mathrm{L}{ }^{-1}$, respectively. The significant wave height averaged $13 \mathrm{~cm}$ (Fig. 6b), wave velocity averaged $6.2 \mathrm{~cm} \mathrm{~s}^{-1}$, and the current velocity changed in direction and also in strength between 0.6 and $5 \mathrm{~cm} \mathrm{~s}^{-1}$ (Fig. 6b) with an average of $2 \mathrm{~cm} \mathrm{~s}^{-1}$. In all 67 of the $15 \mathrm{~min}$ long time intervals used for individual flux estimates, an extremum was found in the cross-correlation of $\widetilde{z}$ and $\widetilde{\mathrm{O}}_{2}$. The optimum time shift corresponded to a minimum correlation for the first part of the deployment (time $<1200 \mathrm{~min}$ ) when the oxygen flux was negative, and a maximum correlation for the rest of the deployment, consistent with an oxygen release (Fig. 6c). Averaged over the night, the correction reduced the flux from the previously reported $-368 \pm 21$ to $-182 \pm 11 \mathrm{mmol} \mathrm{m}^{-2} \mathrm{~d}^{-1}$ (SE, $n=45$ ), or by a factor of 0.49 (Fig. 6d). This corrected flux is still almost twice the size of the flux derived from concurrent in situ chamber measurements (Huettel and Gust, 1992; Berg and Huettel, 2008). The averaged time shift for the entire deployment was $1.11 \pm 0.04 \mathrm{~s}(\mathrm{SE}, n=67)$.

Fluxes shown in Fig. 5 were calculated without a traditional rotation (nullification of the transverse and vertical mean velocities for each 15 min based flux calculation; Lee et al., 2004; Lorrai et al., 2010; Lorke et al., 2013). The current velocities were too small to produce robust rotation estimates for most of the deployment. However, for the first part of the deployment, which had current velocities $>2 \mathrm{~cm} \mathrm{~s}^{-1}$, fluxes calculated without and with rotation equaled $-70.3 \pm 12.0$ and $72.1 \pm 11.0 \mathrm{mmol} \mathrm{m}^{-2} \mathrm{~d}^{-1}$ $(n=3, \mathrm{SE})$, respectively. The rotation angle with the vertical direction was $7^{\circ}$. We see the small difference of $2 \%$ in the flux as an indication of marginal effects of so-called wave bias due to sensor tilt (Grant and Madsen, 1986; Trowbridge, 1998; Shaw and Trowbridge, 2001). The deployment shown in Fig. 6 had larger current velocities, and the calculation of fluxes included the rotation described above.

The filter width of 4 times the wave period in the running average used to separate the wave signal from other less dynamic variations before calculating the cross-correlation of $\widetilde{z}$ and $\widetilde{\mathrm{O}}_{2}$, was not critical for the outcome of the time lag correction. For example, for the data shown in Figs. 5 and 6 , the corrected average nighttime fluxes varied within \pm 4 and $\pm 11 \%$, respectively, when the filter width was changed between 2 and 6 times the wave period.

\section{Discussion}

The results of this study show that oxygen fluxes extracted from eddy covariance data measured at shallow-water sites with short-period waves and low current flows can be affected by a so-called time lag bias. The bias arises because of displacement of the natural vertical oxygen gradient by wave orbital motions, combined with temporal misalignments of the oxygen concentration time series relative to the vertical velocity data. This misalignment cannot be entirely avoided with any eddy covariance instrumentation for aquatic scalar flux measurements available today. As a result, time lag bias, documented here using both modeled and measured data, should be considered when eddy covariance data are measured under such field conditions. Time lag corrections that will minimize this bias are possible, and one is presented in this study.

The theoretical example (Fig. 2), produced with a simple model based on linear wave theory (Appendix A) and fitted to measured data reported by Berg and Huettel (2008), illustrates that the time lag bias can be substantial. The modeled data (Fig. 2a), where all variations were due to wave orbital motions, contain no time lag and represent an idealized situation in which velocity and oxygen data were aligned perfectly in time and space. In this case, there is no time lag bias (time shift $=0$, Fig. 2b). The data also showed that an imposed time shift of the simulated oxygen data relative to the velocity data of only $0.20 \mathrm{~s}$ led to a bias of $100 \%$ of the real flux (Fig. 2b), and that the maximum bias, equaling $180 \%$, was found at a time lag of $0.58 \mathrm{~s}$. The model parameters that gave these substantial time lag biases, including an $11 \mathrm{~cm}$ surface displacement amplitude of the waves and a current velocity of $1 \mathrm{~cm} \mathrm{~s}^{-1}$ (Appendix A), represent common conditions at many near-shore sites. Additional model calculations showed that the maximum bias, relative to the real flux, diminishes rapidly at increasing current velocity due to enhanced turbulent mixing, which reduces the vertical oxygen concentration gradient (Fig. 3, Appendix A). Thus, concern over a substantial time lag bias should only be under relatively low-current flow conditions.

The modeled example also shows that if the oxygen concentration and the vertical velocity are aligned correctly in time, there is no time lag bias (Fig. 2b), which points to the foundation of the correction proposed in this study. This correction identifies the time shift that gives a minimum in cross-correlation (most negative cross-correlation) of the wave-generated fluctuation in oxygen concentration $\left(\widetilde{\mathrm{O}}_{2}\right)$ and the vertical displacement $(\widetilde{z}$, Eq. 1) in situations when the benthic system takes up oxygen (Fig. 4b). By contrast, when the system releases oxygen, a maximum in cross-correlation is sought.

Essentially, the same correction could be defined by using the cross-correlation between $\widetilde{\mathrm{O}}_{2}$ and either the fluctuating water pressure or horizontal wave velocity. The pressure is recorded by standard ADVs at the same sampling frequency 
as the velocity and usually at very low noise levels. However, the type of ADV we are using (a fixed stem Vector from Nortek AS) measures the pressure at its lower end bell which is located $\sim 37 \mathrm{~cm}$ above the ADV's measuring volume, where the velocities are measured. As a result, even a small tilt of the ADV during measurements can introduce a time lag between the cross-correlated variables and lead to false corrections. Similarly, the horizontal wave velocity is split in two when recorded as the ADV's two horizontal $x$ and $y$ velocities. Thus, a rather complex rotation is needed to orient the $x$ component in the direction of the waves (Reimers et al., 2012). In addition, the ADV's $x$ and $y$ velocities are associated with substantially higher noise levels than the vertical $z$ velocity. For these reasons, we relied on the integrated vertical wave velocity (Eq. 1) for the new time lag correction.

An attractive feature of the correction is its simplicity, but it has limitations too as it requires that both the measured vertical velocity and the oxygen concentration contain a clear periodic wave signal. Consequently, at shallow-water sites with photosynthesizing sediment surfaces, it may fail during periods at dusk and dawn when the oxygen flux changes from a release to an uptake, or vice versa, reversing the vertical mean oxygen concentration gradient. Likewise, the correction may also fail if the wave signal cannot be clearly identified due to broad-spectrum wave activity.

The new correction identifies one single time shift that is applied to the entire time interval, typically $15 \mathrm{~min}$, for which a flux is calculated (Figs. 4c, 5c, 6c). Although most of the temporal misalignment of the oxygen data relative to the velocity data is caused by the oxygen sensor's response time, the physical distance between the ADV's measuring volume and the oxygen sensors can play a role too. Because the horizontal wave velocity fluctuates and reverses in direction in each wave cycle, the optimal instantaneous time shift varies somewhat in time. It is unknown how much the use of one single time shift for each individual flux calculation affects the correction.

A future refinement of a time lag correction would be to include two contributions: a larger constant one representing the response time of the oxygen sensor and a smaller dynamic one accounting for the spatial separation between the velocity and the oxygen sensor. The latter contribution, which would obtain both positive and negative values, could easily be determined from known instantaneous horizontal $x$ and $y$ velocities relative to the position of the two sensors. As an added benefit, this proposed correction would be more versatile and work in both unidirectional and wave-driven flows.

Another possible correction would be to remove the flux contribution associated with waves in the frequency domain, instead of the time domain used here. This flux contribution can, for example, be identified fairly easily in the cospectrum or cumulative co-spectrum of the vertical velocity and the oxygen concentration and then be removed. This, or similar approaches, are already widely used to remove wave contributions to Reynolds stresses for wave-dominated nearbottom flows (Bricker and Monismith, 2007). However, such corrections should be applied with caution here because part of the real vertical oxygen flux may be facilitated by wave motions and thus occur at the wave frequency. Wave motions over rough benthic surfaces can give rise to eddies or water parcel ejections at wave frequencies, which expand up into the bottom water, well above the wave boundary layer (Kemp and Simons, 1982; Sleath, 1987; Reidenbach et al., 2007).

The removal of wave contributions to the covariance of vertical and horizontal velocity components, usually termed wave bias in Reynolds stress calculations, addresses a somewhat similar, yet different problem than that focused on here. Wave bias arises from an angular misalignment of the ADV relative to the principal axes of the wave-induced velocity field and is usually caused by a sensor tilt (Grant and Madsen, 1986; Trowbridge, 1998; Shaw and Trowbridge, 2001). Although there is no time lag between the horizontal and the vertical velocity components, which are measured by the same instrument, this angular misalignment can cause significant artificial contributions to Reynolds stress estimates. The time lag bias addressed here is caused by a temporal misalignment between the velocity and the oxygen concentration measured with two individual sensors.

The relatively large time lag bias found in the modeled example (Fig. 2) was also seen in the measured data example recorded over a dense shallow-water seagrass meadow (Fig. 4). The data, covering a $15 \mathrm{~min}$ time interval, had an inherent time lag between the measured oxygen concentration and the velocity and showed a similar high sensitivity to imposed time shifts (Fig. $4 \mathrm{~b}$ vs. $2 \mathrm{~b}$ ). For example, time shifts of $0,0.27$, and $0.47 \mathrm{~s}$ led to eddy fluxes, here representing the real flux plus time lag bias, of $-117,0$, and $40 \mathrm{mmol} \mathrm{m}^{-2} \mathrm{~d}^{-1}$, respectively, or a change from a clear uptake to no flux to a clear release (Fig. 4b). This rather extreme, but real, example also shows how important it is to identify the appropriate time shift to minimize the time lag bias. It further illustrates how the traditional time shift correction, where the maximum numerical flux is sought, would tend to give the maximum time lag bias if negative time shifts were allowed (Fig. $4 \mathrm{~b}$ ) or an unrealistic positive flux, i.e., a net release of oxygen, during nighttime.

The wave-driven periodic variation in $\widetilde{\mathrm{O}}_{2}$ and $\widetilde{z}$ (Fig. 4a) produced a clear minimum in cross-correlation of these two variables that could easily be located (Fig. 4b). This minimum occurred at a time shift of $0.78 \mathrm{~s}$, which gave a corrected flux that was $44 \%$ of the uncorrected flux (Fig. 4c). For reference, the optimal time shift found for the same oxygen sensor in unidirectional river flow was on average $0.83 \mathrm{~s}$ (Berg et al., 2015) and $0.88 \mathrm{~s}$ in the example shown here in Fig. 1. The sensor's own response time $\left(t_{90} \%\right)$ was measured in lab tests to be $0.51 \mathrm{~s}$, when inserted from air into a water bath. The somewhat slower response found in the field, where the sensor was permanently under water, was likely caused by oxygen concentration equilibration through the 
thin boundary layer flow that forms over the oxygen sensing foil (Berg et al., 2015). Through detailed model calculations, Berg et al. (2015) showed that a sensor with this response time will virtually capture the entire flux signal if a time lag correction is applied. Specifically, the underestimation of the flux was found to be less than $5 \%$, even in challenging situations at shallow-water sites with substantial unidirectional current flow, where small rapid eddies dominated the vertical turbulent mixing.

In both of the two longer-period data examples covering 4 and $16 \mathrm{~h}$ (Figs. 5, 6), the new time lag correction led to considerable reductions in the derived eddy flux. In the first example, including 16 individual flux estimates, each based on 15 min time intervals (Fig. 5c), the average corrected flux was $60 \%$ of the uncorrected flux (Fig. 5d), and the time shifts were very similar across all time intervals with an average of $0.85 \mathrm{~s}$ (Fig. 5c). The fact that fluctuating variations in velocity and oxygen concentration included both longer-period wave groups and short-period waves (Fig. 5a) did not prevent the location of optimal time shifts. In the second example, which used data reported earlier by Berg and Huettel (2008) and included 67 individual flux estimates (Fig. 6c), the average corrected nighttime flux was $49 \%$ of the uncorrected flux (Fig. 6d). The individual time shifts showed more variation than in the previous example (Fig. 6c vs. Fig. 5c), which was likely caused by the more pronounced variations in the two horizontal velocities and significant wave height (Fig. 6b). The relatively large average time shift which had an average of $1.11 \mathrm{~s}$ was not expected because Clark-type electrodes used for eddy covariance typically have response times $\left(t_{90 \%}\right)$ between 0.2 and $0.5 \mathrm{~s}$ (Berg et al., 2003; Attard et al., 2014; Rovelli et al., 2015). The most likely reason for the large shift is that the electrode tip was damaged or coated with phyto-detritus or marine mucilage near the beginning of the deployment, notably at min $\sim 460$ (Fig. 6c), when the time shift doubled from a value well below $1 \mathrm{~s}$. However, it should be noted that the large time shift is not the reason for the substantial reduction in oxygen flux associated with the correction. In the examples given above, much smaller time shifts had similar large effects on the flux (Figs. 2b, 4b). The corrected flux is still roughly twice the size of the flux that was measured with in situ chambers deployed concurrently (Fig. 6d). Fundamental differences between the two flux methods, especially when applied to permeable sandy sediments, may explain this disagreement (Glud, 2008; Reimers et al., 2012; Berg et al., 2013).

One effect of using a slow-responding electrode is that it may not capture the full amplitude of a short-period wave signal in oxygen concentration, which, in itself, will add time lag to the recorded periodic wave signal. Specifically, Berg et al. (2015) showed through modeling that when, for example, a $0.5 \mathrm{~Hz}$ sinusoidal wave signal in oxygen concentration is measured with a sensor with a response time ( $\left.t_{90 \%}\right)$ of $0.5 \mathrm{~s}$, a $0.20 \mathrm{~s}$ phase shift, or time lag, is introduced in the recorded data. While this inevitably will add substantial time lag bias to calculated fluxes unless a time lag correction is applied (Figs. 2, 4), it may not have a large effect on the electrode's ability to capture the fluctuations associated with current-driven turbulence. Co-spectral analyses of the oxygen concentration and vertical velocity typically show that only a small fraction of the flux contribution is associated with frequencies higher than $0.5 \mathrm{~Hz}$. So, even if a sizeable portion of the flux signal is lost at high frequencies, it may not affect the total flux significantly (Berg et al., 2015).

The data in Figs. 4 and 5 were measured with a new robust oxygen optode that in lab tests showed no stirring sensitivity (Berg et al., 2015), whereas the data in Fig. 6 were recorded with a Clark-type microelectrode, a sensor type that is known to be affected by the instantaneous water velocity due to its consumption of oxygen (Gust et al., 1987; Revsbech, 1989; Gundersen et al., 1998). Two new studies have focused on how this stirring sensitivity can affect eddy flux estimates in unidirectional flows (Holtappels et al., 2015) and in wave environments (Reimers et al., 2015). We cannot rule out that the oxygen measurements shown in Fig. 6 were affected to some extent by the varying wave velocity. However, typical characteristic patterns of stirring sensitivity in wave environments as documented by Reimers et al. (2015) were not seen in these data. Firstly, stirring sensitivity tends to have an asymmetric dependency on wave velocity, meaning that oxygen concentration is more affected by the velocity from one direction than from the other (Holtappels et al., 2015; Reimers et al., 2015). Signs of this characteristic pattern are easy to identify, but were not seen in our data (Fig. 6a), which contained more of a sinusoidal variation in oxygen concentration. Secondly, if instead stirring sensitivity presents itself as a symmetric dependency on wave velocity, which can happen, for example, if the fluctuating velocity is perpendicular to the sensor, it would appear as fluctuations in concentration with a frequency double that of the wave frequency. This also was not seen in our data (Fig. 6a).

To examine further if stirring sensitivity affected our flux calculations, we assumed that the microelectrode used to measure the data shown in Fig. 6 had a stirring sensitivity as characterized by Holtappels et al. (2015), using their fitting function and specific fitting parameter values $\left(S_{\mathrm{sen}}=\right.$ $0.7 \%, n=0.65$, and $B=30$ ). This particular dependency was found when the electrode was pointing into the mean current which represents the orientation that gives the most dramatic stirring sensitivity (Holtappels et al., 2015). We then applied this function to our data assuming this maximum sensitivity for all horizontal velocity directions. For each time point in our data, we calculated the size of the horizontal velocity; from that, we calculated the associated stirring sensitivity and, finally, the oxygen concentration as it should have been measured in the absence of stirring sensitivity. Fluxes calculated using the same velocity data and the uncorrected and corrected oxygen concentrations were then compared. The average nighttime flux for the original data was $-368.0 \pm 20.6 \mathrm{mmol} \mathrm{m}^{-2} \mathrm{~d}^{-1}(\mathrm{SE}, n=45)$, 
whereas the oxygen data with stirring sensitivity removed gave a flux of $-370.0 \pm 20.5 \mathrm{mmol} \mathrm{m}^{-2} \mathrm{~d}^{-1}(\mathrm{SE}, n=45)$, or a difference of $0.6 \%$. The equivalent calculations for the data with the time lag correction applied gave averaged fluxes of $-181.6 \pm 11.2$ and $-182.7 \pm 11.1 \mathrm{mmol} \mathrm{m}^{-2} \mathrm{~d}^{-1}$, respectively, or, as before, a difference of $0.6 \%$. We, therefore, conclude that stirring sensitivity did not play a significant role in any of the data presented in this study.

\section{Summary and recommendations}

The results presented here illustrate that substantial time lag biases can arise in flux estimates from eddy covariance data measured in the presence of surface gravity waves. The problem is most acute for data measured at shallow-water sites with short-period waves and low current flows. At moderate or high current velocities ( $>5$ to $10 \mathrm{~cm} \mathrm{~s}^{-1}$ ), the bias usually is insignificant under typical field conditions. In most situations, the problem can be effectively addressed by applying the appropriate correction. A simple, but helpful, additional flux calculation that will indicate if time lag bias should be of concern is to impose a small time shift $(\sim 0.1-0.2 \mathrm{~s})$ on the measured raw data and recalculate the flux. If a significant change in flux is found, time lag bias should be investigated further.

The widely used traditional time shift correction in unidirectional flows, where the maximum numerical flux is sought, tends to amplify the time lag bias, or give unrealistic flux estimates and should not be applied if clear wave signals are seen in the data.

Although the new correction presented here will minimize the time lag bias, one should always strive to measure eddy covariance data using oxygen sensors with minimum time delay and to measure both the velocity and the oxygen concentration as close to the same location as possible.

We encourage more work on these issues because wave motion more often than not appears in eddy covariance data measured at shallow-water marine sites. 


\section{Appendix A}

A model based on linear wave theory for orbital velocity associated with progressive waves and their effect on the oxygen concentration at a given height over the sediment surface was developed and fitted to existing measured eddy covariance data. The model was used to generate theoretical time series of the wave orbital velocity and the corresponding oxygen concentration at the measuring point of an eddy covariance system. These time series were then shifted in time relative to one another to illustrate how a time lag can bias the flux calculation.

The horizontal and vertical wave orbital velocity components, $\widetilde{u}$ and $\widetilde{w}$, can be expressed as (Dean and Dalrymple, 1991)

$\tilde{u}=a \omega \frac{\cosh (k h)}{\sinh (k H)} \cos (-\omega t)$

and

$\widetilde{w}=a \omega \frac{\sinh (k h)}{\sinh (k H)} \sin (-\omega t)$,

where $a$ is the wave surface displacement amplitude, $\omega$ the angular frequency $(\omega=2 \pi f ; f$ is the wave frequency in $\mathrm{Hz}), k$ is the angular wavenumber $(k=2 \pi / \lambda ; \lambda$ is the wave length), $h$ is the measuring height above the bottom, and $H$ is the total water depth.

A value of $k$ (or $\lambda$ ) is difficult to assess from measured velocity time series but can be estimated from the dispersion equation (Dean and Dalrymple, 1991) that relates $k, \omega$, and $H$ as $\omega=\sqrt{g k \tanh (k H)}$, where $g$ is the acceleration due to gravity. Rearranging this equation, $k$ can be calculated by iteration as

$k_{j+1}=\frac{\omega^{2}}{g \tanh \left(k_{j} H\right)}$,

where $j$ is the iteration step number.

The relative vertical displacement of a water parcel, $\widetilde{z}$, can be found by integrating Eq. (A2):

$\widetilde{z}=\int_{0}^{t} \widetilde{w} \mathrm{~d} t=a \frac{\sinh (k h)}{\sinh (k H)} \cos (-\omega t)$.
Table A1. Wave model parameters used to produce results in Figs. 2 and 3 .

\begin{tabular}{ll}
\hline Water depth, $H$ & $140 \mathrm{~cm}$ \\
Measuring height, $h$ & $12 \mathrm{~cm}$ \\
Wave surface displacement amplitude, $a$ & $11 \mathrm{~cm}$ \\
Wave frequency, $f$ & $0.43 \mathrm{~s}^{-1}$ \\
Wavenumber, $k$ & $0.0089 \mathrm{rad} \mathrm{cm}^{-1}$ \\
Current velocity, $\bar{u}$ & $1 \mathrm{~cm} \mathrm{~s}-1$ \\
Sediment surface roughness parameter, $z_{0}$ & $0.2 \mathrm{~cm}$ \\
Benthic oxygen flux (uptake), $J_{\text {benthic }}$ & $-368 \mathrm{mmol} \mathrm{m}^{-2} \mathrm{~d}^{-1}$ \\
\hline
\end{tabular}

Assuming that a vertical gradient in mean oxygen concentration, $\mathrm{d} \overline{\mathrm{O}}_{2} / \mathrm{d} z$, exists near the bottom due to the uptake or release of oxygen by the sediment, the relative concentration fluctuation can be approximated to first order as

$\widetilde{\mathrm{O}}_{2} \sim \frac{\mathrm{d} \overline{\mathrm{O}}_{2}}{\mathrm{~d} z}(-\widetilde{z})=-a \frac{\mathrm{d} \overline{\mathrm{O}}_{2}}{\mathrm{~d} z} \frac{\sinh (k h)}{\sinh (k H)} \cos (-\omega t)$.

The vertical gradient can be estimated from Fick's first law of diffusion applied to vertical turbulent mixing as

$\frac{\mathrm{d} \overline{\mathrm{O}}_{2}}{\mathrm{~d} z}=-\frac{J_{\text {benthic }}}{E_{z}}$,

where $J_{\text {benthic }}$ is an assumed known benthic flux and $E_{z}$ is the turbulent eddy diffusivity. The latter can be estimated by the semiempirical equation (Businger and Arya, 1975)

$E_{z}=\kappa u_{*} h e^{-2 h / H}$,

where $\kappa$ is von Karman's constant $(0.41)$ and $u_{*}$ is the friction velocity. Finally, $u_{*}$, the sediment surface roughness parameter, $z_{0}$, and the current velocity at the measuring height, $\bar{u}$, are related by the classic log velocity profile

$\bar{u}=\frac{u_{*}}{\kappa} \ln \left(\frac{h}{z_{0}}\right)$.

The model was applied to the eddy covariance data reported by Berg and Huettel (2008) for a shallow-water sandy sediment exposed to waves. Model parameter values in Table A1 were found to give good agreement between modeled and measured fluctuations in velocity and oxygen concentration. 


\section{Appendix B}

The application of the new time lag correction is straightforward and consists of the stepwise calculations outlined below. The input consists of two parallel time series, the vertical velocity, $w_{i}$, and the oxygen concentration, $\mathrm{O}_{2 i}$, each with $N$ values $\Delta t$ apart.

Compute the following:

1. $z_{1}=0$. For $i=2$ to $N$ : calculate $z_{i}=z_{i-1}+w_{i} \Delta t$.

2. For $i=1$ to $N$ : de-trend $z_{i}$ to get the relative vertical displacement due to waves, $\widetilde{z}_{i}$, using, for example, a running average with a filter width of 4 times the wave period.
3. For $i=1$ to $N$ : de-trend $\mathrm{O}_{2 i}$ in the same way to get $\widetilde{\mathrm{O}}_{2 i}$.

4. Find the minimum or maximum in cross-correlation of $\widetilde{z}_{i}$ and $\widetilde{\mathrm{O}}_{2 i}$, depending on whether the sediment consumes or releases oxygen, respectively.

5. Shift the $\mathrm{O}_{2 i}$ data (input data) according to (4), and calculate the flux as usual. 


\section{Data availability}

To facilitate more work on eddy flux calculation from data measured in the presence of waves, the data used in this study can be downloaded from http://faculty.virginia.edu/berg/.

Acknowledgements. We thank two anonymous reviewers, reviewer Moritz Holtappels, and Associate Editor Jack Middelburg for helpful and constructive comments on the manuscript. We also thank Rachel E. Michaels for proof-reading the manuscript. This study was supported by grants from the National Science Foundation (OCE-1061108, OCE-1061218, OCE-1061364, OCE-1334848, and OCE 1334117) and the University of Virginia.

Edited by: J. Middelburg

\section{References}

Attard, K. M., Glud, R. N., McGinnis, D. F., and Rysgaard, S.: Seasonal rates of benthic primary production in a Greenland fjord measured by aquatic eddy correlation, Limnol. Oceanogr., 59, 1555-1569, 2014.

Attard, K. M., Stahl, H., Kamenos, N. A., Turner, G., Burdett, H. L., and Glud, R. N.: Benthic oxygen exchange in a live coralline algal bed and an adjacent sandy habitat: an eddy covariance study, Mar. Ecol.-Prog. Ser., 535, 99-115, doi:10.3354/meps11413, 2015.

Baldocchi, D. D.: Assessing the eddy covariance technique for evaluating carbon dioxide exchange rates of ecosystems: past, present and future, Global Change Biol., 9, 479-492, 2003.

Berg, P. and Huettel, M.: Monitoring the seafloor using the noninvasive eddy correlation technique: Integrated benthic exchange dynamics, Oceanography, 21, 164-167, 2008.

Berg, P., Roy, H., Janssen, F., Meyer, V., Jorgensen, B. B., Huettel, M., and de Beer, D.: Oxygen uptake by aquatic sediments measured with a novel non-invasive eddy-correlation technique, Mar. Ecol.-Prog. Ser., 261, 75-83, 2003.

Berg, P., Roy, H., and Wiberg, P. L.: Eddy correlation flux measurements: The sediment surface area that contributes to the flux, Limnol. Oceanogr., 52, 1672-1684, 2007.

Berg, P., Glud, R. N., Hume, A., Stahl, H., Oguri, K., Meyer, V., and Kitazato, H.: Eddy correlation measurements of oxygen uptake in deep ocean sediments, Limnol. Oceanogr.-Meth., 7, 576-584, 2009.

Berg, P., Long, M. H., Huettel, M., Rheuban, J. E., McGlathery, K. J., Howarth, R. W., Foreman, K. H., Giblin, A. E., and Marino, R.: Eddy correlation measurements of oxygen fluxes in permeable sediments exposed to varying current flow and light, Limnol. Oceanogr., 58, 1329-1343, 2013.

Berg, P., Koopmans, D., Huettel, M., Li, H., Mori, K., and Wüest, A.: A new robust dual oxygen-temperature sensor for aquatic eddy covariance measurements, Limnol. Oceanogr.Meth., doi:10.1002/lom3.10071, in press, 2015.

Boudreau, B. P. and Jorgensen, B. B.: The benthic boundary layer: Transport processes and biogeochemistry, Oxford University Press, Oxford, UK, 2001.
Bricker, J. D. and Monismith, S. G.: Spectral wave-turbulence decomposition, J. Atmos. Ocean. Tech., 24, 1479-1487, 2007.

Businger, J. A. and Arya, S.: Height of the mixed layer in the stably stratified planetary boundary layer, Adv. Geophys., 18, 73-92, 1975.

Cathalot, C., Van Oevelen, D., Cox, T., Kutti, T., Lavaleye, M., Duineveld, G., and Meysman, F. J. R.: Cold-water coral reefs and adjacent sponge grounds: Hotspots of benthic respiration and organic carbon cycling in the deep sea, Frontiers in Marine Science, 2, 37, doi:10.3389/fmars.2015.00037, 2015.

Chipman, L., Huettel, M., Berg, P., Meyer, V., Klimant, I., Glud, R. N., and Wenzhoefer, F.: Oxygen optodes as fast sensors for eddy correlation measurements in aquatic systems, Limnol. Oceanogr.-Meth., 10, 304-316, 2012.

Crusius, J., Berg, P., Koopmans, D. J., and Erban, L.: Eddy correlation measurements of submarine groundwater discharge, Mar Chem., 109, 77-85, 2008.

Dean, R. G. and Dalrymple, R. A.: Water Wave Mechanics for Engineers and Scientists, World Scientific, Singapore, 1991.

Donis, D., Holtappels, M., Noss, C., Cathalot, C., Hancke, K., Polsenaere, P., Wenzhöfer, F., Lorke, A., Meysman, F. J. R., and Glud, R. N.: An assessment of the precision and confidence of aquatic eddy correlation measurements, J. Atmos. Ocean. Tech., 32, 642-655, 2015.

Fan, S. M., Wofsy, S. C., Bakwin, P. S., Jacob, D. J., and Fitzjarrald, D. R.: Atmosphere-biosphere exchange of $\mathrm{CO}_{2}$ and $\mathrm{O}_{3}$ in the central Amazon forest, J. Geophys. Res.-Atmos., 95, 1685116864, 1990.

Fukuchi, M., Legendre, L., and Hoshiai, T.: The Canada-Japan SARES project on the first-year ice of Saroma-ko Lagoon (northern Hokkaido Japan) and Resolute Passage (Canada High Arctic), J. Marine Syst., 11, 1-8, 1997.

Glud, R. N.: Oxygen dynamics of marine sediments, Mar. Biol. Res., 4, 243-289, 2008.

Glud, R. N., Berg, P., Hume, A., Batty, P., Blicher, M. E., Lennert, K., and Rysgaard, S.: Benthic O-2 exchange across hard-bottom substrates quantified by eddy correlation in a sub-Arctic fjord, Mar. Ecol.-Prog. Ser., 417, 1-12, 2010.

Grant, W. D. and Madsen, O. S.: The continental shelf bottom boundary layer, Annu. Rev. Fluid Mech., 18, 265-306, 1986.

Gundersen, J. K., Ramsing, N. B., and Glud, R. N.: Predicting the signal of O-2 microsensors from physical dimensions, temperature, salinity, and O-2 concentration, Limnol. Oceanogr., 43, 1932-1937, 1998.

Gust, G., Booij, K., Helder, W., and Sundby, B.: On the velocity sensivity (stirring effect) of polarographic oxygen microelectodes, Neth. J. Sea. Res., 21, 255-263, 1987.

Holtappels, M., Noss, C., Hancke, K., Cathalot, C., McGinnis, D., Lorke, A., and Glud, R. N.: Aquatic Eddy correlation: Quantifying the artificial flux caused by stirring sensitive $\mathrm{O}_{2}$ sensors, Plos One, 10, e0116564, doi:10.1371/journal.pone.0116564, 2015.

Huettel, M. and Gust, G.: Solute release mechanisms from confined sediment cores in stirred benthic chambers and flume flows, Mar. Ecol. Prog.-Ser., 82, 187-197, 1992.

Hume, A. C., Berg, P., and McGlathery, K. J.: Dissolved oxygen fluxes and ecosystem metabolism in an eelgrass (Zostera marina) meadow measured with the eddy correlation technique, Limnol. Oceanogr., 56, 86-96, 2011. 
Kemp, P. H. and Simons, R. R.: The interaction between waves and a turbulent current: waves propagating with the current, J. Fluid Mech., 116, 227-250, 1982.

Kundu, P. K.: Fluid Mechanics, 638 pp., Academic Press, San Diego, California, 1990.

Kuwae, T., Kamio, K., Inoue, T., Miyoshi, E., and Uchiyama, Y.: Oxygen exchange flux between sediment and water in an intertidal sandflat, measured in situ by the eddy-correlation method, Mar. Ecol.-Prog. Ser., 307, 59-68, 2006.

Lee, X., Massman, W., and Law, B.: Handbook of micrometeorology: A guide for surface flux measurement and analysis, Kluwer Academic Publishers, 2004.

Long, M. H., Berg, P., de Beer, D., and Zieman, J. C.: In Situ Coral Reef Oxygen Metabolism: An Eddy Correlation Study, Plos One, 8, e58581, doi:10.1371/journal.pone.0058581, 2013.

Long, M. H., Berg, P., McGlathery, K. M., and Zieman, J. C.: SubTropical Seagrass Ecosystem Metabolism Measured by Eddy Correlation, Mar. Ecol.-Prog Ser., 529, 75-90, 2015.

Lorke, A., McGinnis, D. F., and Maeck, A.: Eddy-correlation measurements of benthic fluxes under complex flow conditions: Effects of coordinate transformations and averaging time scales, Limnol. Oceanogr.-Meth., 11, 425-437, 2013.

Lorrai, C., McGinnis, D. F., Berg, P., Brand, A., and Wüest, A.: Application of oxygen eddy correlation in aquatic systems, J. Atmos. Ocean. Tech., 27, 1533-1546, 2010.

McGinnis, D. F., Berg, P., Brand, A., Lorrai, C., Edmonds, T. J., and Wuest, A.: Measurements of eddy correlation oxygen fluxes in shallow freshwaters: Towards routine applications and analysis, Geophys. Res. Lett., 35, 1-5, 2008.

McPhee, M. G.: Turbulent heat flux in the upper ocean under sea ice, J. Geophys. Res., 97, 5365-5379, 1992.

Murniati, E., Geissler, S., and Lorke, A.: Short-term and seasonal variability of oxygen fluxes at the sediment-water interface in a riverine lake, Aquat. Sci., 77, 183-196, 2015.

Partch, E. N. and Smith, J. D.: Time dependent mixing in a salt wedge estuary, Estuar. Coast. Mar. Sci., 6, 3-19, 1978.

Priestley, C. and Swinbank, W.: Vertical transport of heat by turbulence in the atmosphere, P. Roy. Soc. Lond. A Mat., 189, 543561,1947

Rattray, M. and Mitsuda, E.: Theoretical analysis of conditions in a salt wedge, Estuar. Coast. Mar. Sci., 2, 375-394, 1974.
Reidenbach, M. A., Koseff, J. R., and Monismith, S. G.: Laboratory experiments of fine-scale mixing and mass transport within a coral canopy, Phys. Fluids, 19, 075107, doi:10.1063/1.2752189, 2007.

Reimers, C. E., Özkan-Haller, T., Berg, P., Devol, A., McCannGrosvenor, K., and Sanders, R. D.: Benthic oxygen consumption rates during hypoxic conditions on the Oregon continental shelf: Evaluation of the eddy correlation method, J. Geophys. Res., 117, 1-18, 2012.

Reimers, C. E., Özkan-Haller, T., Albright, A., and Berg, P.: Microelectrode velocity effects and aquatic eddy covariance measurements under waves, J. Atmos. Ocean. Tech., in review, 2015.

Revsbech, N. P.: An oxygen microsensor with a guard cathode, Limnol. Oceanogr., 34, 474-478, 1989.

Rheuban, J. E. and Berg, P.: The effects of spatial and temporal variability at the sediment surface on aquatic eddy correlation flux measurements, Limnol. Oceanogr.-Meth., 11, 351-359, 2013.

Rheuban, J. E., Berg, P., and McGlathery, K. J.: Multiple timescale processes drive ecosystem metabolism in eelgrass (Zostera marina) meadows, Mar. Ecol.-Prog. Ser., 507, 1-13, 2014.

Rovelli, L., Attard, K. M., Bryant, L. D., Flögel, S., Stahl, H. J., Roberts, M., Linke, P., and Glud, R. N.: Benthic $\mathrm{O}_{2}$ uptake of two cold-water coral communities estimated with the non-invasive eddy-correlation technique, Mar. Ecol.-Prog. Ser., 525, 97-104, 2015.

Shaw, W. J. and Trowbridge, J. H.: The Direct Estimation of NearBottom Turbulent Fluxes in the Presence of Energetic Wave Motions, J. Atmos. Ocean. Tech., 18, 1540-1557, 2001.

Shirasawa, K., Ingram, R. G., and Hudier, E. J. J.: Oceanic heat fluxes under thin sea ice in Saroma-ko Lagoon, Hokkaido Japan, J. Marine Syst., 11, 9-19, 1997.

Sleath, J.: Turbulent oscillatory flow over rough beds, J. Fluid Mech., 182, 369-409, 1987.

Swinbank, W. C.: The measurement of vertical transfer of heat and water vapor by eddies in the lower atmosphere, J. Meteorol., 8, 115-145, 1951.

Trowbridge, J.: On a technique for measurement of turbulent shear stress in the presence of surface waves, J. Atmos. Ocean. Tech., 15, 290-298, 1998. 